\title{
White-Collar Workers' Self-Reported Physical Symptoms Associated With Using Computers
}

\author{
Leena Korpinen \\ Environmental Health, Tampere University of Technology, Tampere, Finland \\ Faculty of Medicine, University of Tampere, Tampere, Finland
}

Rauno Pääkkönen

Finnish Institute of Occupational Health, Tampere, Finland

\section{Fabriziomaria Gobba}

Department of Public Health Sciences, University of Modena and Reggio Emilia, Modena, Italy

The aim of our work was to study the physical symptoms of upper-and lower-level white-collar workers using a questionnaire. The study was cross-sectional with a questionnaire posted to 15000 working-age persons. The responses (6121) included 970 upper-and 1150 lower-level white-collar workers. In the upper-and lower-level white-collar worker groups, 45.7 and 56.0\%, respectively, had experienced pain, numbness and aches in the neck either pretty often or more frequently. When comparing daily computer users and nonusers, there were significant differences in pain, numbness and aches in the neck or in the shoulders. In addition, age and gender influenced some physical symptoms. In the future, it is essential to take into account that working with computers can be especially associated with physical symptoms in the neck and in the shoulders when workers use computers daily.

white-collar workers symptoms questionnaire computer

\section{INTRODUCTION}

Several recent studies showed that a relatively high proportion of workers often reported various types of physical or mental symptoms. For example, in the Fourth European Working Conditions Survey, 24.7, 22.8 and $15.5 \%$ of the examined workers reported backache, muscular pain and headaches, respectively [1]. In Perkiö-Mäkelä, Hirvonen, Elo, et al.'s Finnish study, 3122 persons, aged 25-64, were interviewed by phone; the number of working persons was 2229 (51\% male and 49\% female) [2]. Symptoms of musculoskeletal and connective tissue disorders were enquired about, and the results were as follows: pain in the neck/ shoulder $48 \%$, in the arms and shoulders $32 \%$, in the hip and lower back $28 \%$, in the hips and legs $24 \%$ and in the wrists and fingers $19 \%$.

Gourmelen, Chastang, Ozguler, et al. studied the prevalence of lower back pain in the French population aged 30-64; they used data from the National Health Survey 2002-2003 [3]. The respondents were asked about the duration of lower back pain in the past 12 months. The results showed that over half of the population had expe-

The assistance of the staff (Noomi Suuronen, Jari Latva-Teikari and Riitta Lehtelä) of the Department of Energy and Process Engineering, Environmental Health, Tampere University of Technology is gratefully acknowledged. Special thanks go to Professor Irma Virjo, Faculty of Medicine, Tampere University, for her advice on designing the questionnaire and to Maarit Pakarinen, SPSS Finland Oy, for her advice on statistical analyses.

Correspondence and requests for offprints should be sent to Leena Korpinen, EPR, Environmental Health, Tampere University of Technology, P.O. Box 589, FI-33101 Tampere, Finland. E-mail: leena.korpinen@tut.fi. 
rienced lower back pain lasting at least one day in the past 12 months [3].

Differences between genders were also reported in the prevalence of musculoskeletal symptoms. Straker, Smith, Bear, et al. examined the influence of this factor on the relationships between computer use, habitual posture and neck/shoulder pain in adolescents [4]. Forty-five percent of women and $52 \%$ of men used the computer for up to $7 \mathrm{~h}$ per week. However, $34.7 \%$ of the women reported neck/shoulder pain, but only $23.1 \%$ of the men, supporting the hypothesis of an effect of gender on the relationships among computer use, posture and neck/shoulder pain [4].

In recent years, the use of new technical equipment has increased. Information acquisition has become easier with various kinds of mobile services. Work is no longer bound to a specific time or place. According to the Fourth European Working Condition Survey Report, 26\% of workers worked with a computer either all or almost all of the time. In 1990, the equivalent figure was $\sim 13 \%$ [1]. According to Statistics Finland, 99\% of Finnish households had one or more mobile phones in 2008 [5]. Between 2001 and 2006, the number of mobile phones increased by $31.8 \%$ [6]. In 2006, $100 \%$ of 18-64-year-old upper-level white-collar workers and students used computers, $97 \%$ of lower-level white-collar workers, $89 \%$ of other entrepreneurs, $83 \%$ of blue-collar workers, $79 \%$ of farmers and $57 \%$ of pensioners [7].

Musculoskeletal complaints are common among computer workers; they may be associated with ergonomic and psychosocial factors at work $[8$, $9,10,11]$. Stress is also a common problem in working life; it is related to psychosocial factors and may be associated with musculoskeletal complaints [8, 12]. Eklöf, Ingelgård and Hagberg [8] and Eklöf and Hagberg [13] studied Swedish white-collar VDU (visual display unit) workers. Eklöf et al. aimed to explore cross-sectional and prospective correlations between characteristics of working-environment change processes and working-environment and health indicators, in white-collar users of VDUs [8]. According to their results on participation and integration in efforts to improve the working environment, psychological demands and stress were consistently negatively associated with health indictors, while social support had a positive effect. Participation and integration may be particularly relevant for demands, social support and stress [8]. Eklöf and Hagberg's aim was to test whether feedback and discussion of ergonomic and psychosocial working-environment data during one short session with an individual, groups or supervisors of VDU workers had an effect on (a) the quality of implemented modifications in workplace design, working technique or psychosocial aspects; (b) psychological demands, decision latitude and social support; (c) comfort during computer work, emotional stress and prevalence of musculoskeletal symptoms or eye discomfort. They found that the positive effect on social support was indicated by feedback to supervisors [13].

The aim of our work was to study physical symptoms in upper-level white-collar workers (workers engaged in administrative or managerial duties, designing, research, teaching) and lower-level white-collar workers (clerical duties and supervision) using a questionnaire, and to compare the symptoms in (a) workers who used a computer daily and workers who did not and (b) upper- and lower-level white-collar workers. In addition, the aim was to analyse how symptoms were associated with using desktop computers, portable computers or mini-computers, psychosocial factors and background information such as age and gender. Our work was part of a larger questionnaire study on the possible influence of new technical equipment on the health of the working-age population. The results of ergonomic health aspects and mental symptoms in all data have been reported earlier [14, 15].

\section{METHODS}

\subsection{Study Population and Questionnaire}

In October 2002, a questionnaire was sent to 15000 Finns. As the study focused on the working-age population, only people aged $18-65$ were included. Their names and addresses were obtained as a random sample from the Finnish Population Register Centre. The study design was 
approved by the Ethical Committee (Pirkanmaa Health District, Finland, decision R02099). The questionnaire was divided into six sections. Section 1 dealt with background information such as age, gender, marital status, education, occupation and home county. Section 2 mapped the familiarity and use of technical devices at leisure and at work: desktop computers, portable computers, hand-held computers, communicators, the Internet, mobile phones, electronic marketplaces/commerce, teletext, digital television and associated services. The choices for questions "How often do you use the following equipment or services for leisure?" and "How often do you use the following equipment or services at work?" were cannot say, not at all, less than monthly, monthly, weekly and daily. The questionnaire did not include any time limit and no specific time threshold was given to the participants, so the time limit decision was based on self-evaluation of the responder. Sections 3-5 focused on physical load and ergonomics, psychological welfare, and accidents and close-call situations at leisure or at work, respectively. The last part was an open-ended question "other observations concerning technology and health". The details of the questionnaire have been reported earlier [14].

\subsection{Statistical Analysis}

First, only white-collar workers in working life were chosen. In addition, subgroups of upperand lower-level workers were made from the data. The statistical analyses were done with SPSS version 19. The options for Questions 13 and 16 were cannot say, not at all, sometimes - 0 (no symptoms), pretty often-1, often-2 and very often-3.

Question 13: Have you had an ache, pain or numbness in the following body part during the past 12 months?

13a. in wrists and fingers;

13b. in elbows and forearms;

13c. in neck;

13d. in shoulders;

13e. in hip and lower back;

13f. in feet.

\section{Question 16: Have you suffered}

16a. sleeping disorders/disturbances;

16b. depression;

16c. exhaustion at work;

16d. substance addiction;

16e. anxiety;

16f. fear situations during the past 12 months?

In the first analysis of Questions 13a-f and 16a-f, we used an independent samples MannWhitney $U$ test. In the analyses of all upper- and lower-level white-collar workers, we compared (a) respondents who used a desktop computer daily at work and nonusers, (b) respondents who used a portable computer or a minicomputer (e.g., a communicator) at work daily and nonusers, (c) female respondents who used a desktop computer at work daily and nonusers and (d) male respondents who used a desktop computer at work daily and nonusers.

In the second analysis, we also used an independent samples Mann-Whitney $U$ test to compare Questions 13a-f between upper- and lower-level white-collar workers with subgroups: (a) all respondents in working life, (b) respondents who used a desktop computer daily at work, (c) female respondents who used a desktop computer at work daily, (d) male respondents who used a desktop computer at work daily and (e) respondents who used a portable computer or a mini-computer (e.g., a communicator) at work daily.

In the third analysis, age groups were established (under 20, 21-30, 31-40, 41-50, 51-60 and over 60). The statistical analyses consisted of general linear models (GLM) with the symptoms assigned as target variables. Also, certain procedures were made for the explanatory variables. In the analyses for Questions 13a-f, the model factors were age, gender, daily use of a desktop computer at work (Q11b); daily use of a portable computer or mini-computer (e.g., a communicator) at work (Q11e); depression, pretty often or more frequently (Q16b); and two-way interactions age $\times$ gender. In this study, $p=.05$ was chosen. 


\section{RESULTS}

\subsection{Background Information}

During the winter of 2002-2003, a total of 6121 responses arrived. Thus, the response rate was $41 \%$. The mean age \pm standard deviation was $41.3 \pm 13.1$ years. The data included 366 entrepreneurs, 105 farmers, 971 upper-level whitecollar workers (administrative or managerial duties, designing, research, teaching), 1149 lower-level white-collar workers (clerical duties and supervision) and 1548 blue-collar workers (industrial workers, distributive and service trade). The upper-level white-collar workers were 21-66 years old, $M(S D) 42.0 \pm 10.4$. The lowerlevel white-collar workers were 19-65 years old, $M(S D) 43.0 \pm 10.8$. One respondent in each of the two groups (i.e., upper- and lower-level workers) answered incorrectly that his or her age was 16 . We did not include that in the calculations of mean ages, because the sample from the Finnish Population Register Centre included only people aged 18-65 years. In addition, one person in the group of upper-level white-collar workers was
65 years old according to the Finnish Population Register Centre, but 66 according to the answer in the questionnaire; this subject was included in the calculations. Table 1 presents background information and the results of all persons in working life, upper- and lower-level white-collar workers, and shows the number of responses and the percentage values. In Q11b and Q11e, the number of daily answers is given. For Questions 13a-f and 16a-f, Table 1 shows the number of pretty often, often and very often answers.

In this study, $50.2 \%$ of working persons had pretty often or more frequently experienced pain, numbness or aches in the neck, $30.6 \%$ had pain in the shoulders and $31.9 \%$ in the hips and lower back. In the group of upper-level whitecollar workers, $45.7 \%$ had pretty often or more frequently experienced pain, numbness or aches in the neck, $24.3 \%$ in the hip and lower back and $23.2 \%$ in the shoulders. In the group of lower-level white-collar workers, $56.0 \%$ had experienced pain, numbness or aches in the neck, $35.8 \%$ in the shoulders and $32.1 \%$ in the hip and lower back.

TABLE 1. A Summary of Background Information: Daily Use of Computers at Work; Mental Symptoms; and Experienced Pain, Numbness or Aches (Positive Answers Including Pretty Often, Often, Very Often)

\begin{tabular}{|c|c|c|c|c|c|c|}
\hline \multirow[b]{2}{*}{ Topic } & \multicolumn{6}{|c|}{ White-Collar Workers (\%) } \\
\hline & \multicolumn{2}{|c|}{ All at Work } & \multicolumn{2}{|c|}{ Upper-Level $^{1}$} & \multicolumn{2}{|c|}{ Lower-Level $^{2}$} \\
\hline \multicolumn{7}{|l|}{ Gender } \\
\hline women & 2414 & $(55.4)$ & 478 & $(49.3)$ & 795 & $(69.3)$ \\
\hline men & 1947 & $(44.6)$ & 492 & $(50.7)$ & 353 & $(30.7)$ \\
\hline \multicolumn{7}{|l|}{ Q11 Daily use at work } \\
\hline b. use of desktop computer & 2728 & $(62.5)$ & 795 & $(81.9)$ & 1037 & $(90.2)$ \\
\hline e. use of portable computer or mini-computer & 426 & $(9.8)$ & 251 & $(25.8)$ & 86 & $(7.5)$ \\
\hline \multicolumn{7}{|l|}{ Q13 Experienced pain, numbness or aches } \\
\hline a. in wrists or fingers & 855 & $(19.6)$ & 150 & $(15.4)$ & 259 & $(22.6)$ \\
\hline b. in elbows or forearms & 607 & $(13.9)$ & 108 & $(11.1)$ & 183 & $(15.9)$ \\
\hline c. in neck & 2194 & $(50.2)$ & 443 & $(45.7)$ & 644 & $(56.0)$ \\
\hline d. in shoulders & 1338 & $(30.6)$ & 225 & $(23.2)$ & 412 & $(35.8)$ \\
\hline e. in hip and lower back & 1396 & (31.9) & 237 & (24.3) & 369 & (32.1) \\
\hline f. in feet & 991 & $(22.7)$ & 145 & $(14.9)$ & 239 & $(20.9)$ \\
\hline \multicolumn{7}{|l|}{ Q16 Mental symptoms } \\
\hline a. sleeping disorders/disturbances & 708 & $(16.2)$ & 171 & $(17.6)$ & 228 & $(19.8)$ \\
\hline b. depression & 350 & $(8.0)$ & 82 & $(8.4)$ & 106 & $(9.2)$ \\
\hline c. exhaustion at work & 853 & (19.5) & 190 & (19.6) & 251 & $(21.8)$ \\
\hline d. substance addiction & 68 & $(1.6)$ & 8 & $(0.8)$ & 19 & $(1.7)$ \\
\hline e. anxiety & 242 & $(5.5)$ & 63 & $(6.5)$ & 69 & (6.0) \\
\hline f. fear situations & 108 & $(2.5)$ & 25 & $(2.6)$ & 25 & (2.2) \\
\hline
\end{tabular}

Notes. 1-administrative or managerial duties, designing, research, teaching; 2 -clerical duties and supervision. 


\subsection{Results of the Mann-Whitney $U$ Test}

Table 2 shows the analyses of Questions 13a-f (physical symptoms). In the analyses of the data of all white-collar workers, there were significant differences in the symptoms (ache, pain or numbness in the neck) in the comparison of daily desktop computer users and nonusers. The differ-

TABLE 2. Comparison Between Computer Users and Nonusers; an Independent Samples MannWhitney U Test Analysis for Question 13 (Data for Upper- and Lower-Level White-Collar Workers)

\begin{tabular}{|c|c|c|c|c|c|c|}
\hline \multirow[b]{3}{*}{ Participants } & \multicolumn{6}{|c|}{$\begin{array}{l}\text { Q13: Have You Had an Ache, Pain or Numbness in the Following } \\
\text { Body Part During the Past } 12 \text { Months? }\end{array}$} \\
\hline & $\mathbf{a}$ & b & c & d & e & $\mathbf{f}$ \\
\hline & $\begin{array}{l}\text { Asymp. Sig. } \\
\text { (2-tailed) }\end{array}$ & $\begin{array}{l}\text { Asymp.Sig. } \\
\text { (2-tailed) }\end{array}$ & $\begin{array}{l}\text { Asymp. Sig. } \\
\text { (2-tailed) }\end{array}$ & $\begin{array}{l}\text { Asymp. Sig. } \\
\text { (2-tailed) }\end{array}$ & $\begin{array}{l}\text { Asymp.Sig. } \\
\text { (2-tailed) }\end{array}$ & $\begin{array}{l}\text { Asymp.Sig. } \\
\text { (2-tailed) }\end{array}$ \\
\hline \multicolumn{7}{|l|}{ White-collar workers } \\
\hline users ${ }^{1}$-nonusers & .395 & .800 & $.032^{* *}$ & .053 & .255 & .418 \\
\hline laptop users ${ }^{2}-$ nonusers & .872 & .782 & $.004^{\star *}$ & $.037^{\star \star}$ & .190 & $.039^{\star *}$ \\
\hline female users-nonusers & .223 & .460 & $.011^{\star \star}$ & .086 & .433 & .555 \\
\hline male users-nonusers & .782 & .507 & .989 & .345 & .382 & .563 \\
\hline \multicolumn{7}{|c|}{ Upper-level white-collar workers } \\
\hline users-nonusers & .981 & .848 & .759 & .548 & .519 & .302 \\
\hline laptop users-nonusers & $.031^{* *}$ & .252 & .328 & .789 & .363 & .279 \\
\hline female users-nonusers & .696 & .674 & .225 & .535 & .697 & .517 \\
\hline male users-nonusers & .812 & .431 & .803 & .348 & .303 & .725 \\
\hline \multicolumn{7}{|c|}{ Lower-level white-collar workers } \\
\hline users-nonusers & .589 & .987 & .051 & .273 & .784 & .482 \\
\hline laptop users-nonusers & .540 & .578 & .147 & .572 & .497 & .513 \\
\hline female users-nonusers & .680 & .805 & .127 & .513 & .984 & .446 \\
\hline male users-nonusers & .879 & .925 & .789 & .733 & .907 & .624 \\
\hline
\end{tabular}

Notes. ${ }^{* *} p<.05$, asymp. sig.-asymptotic significance; a-in wrists and fingers, b-in elbows and forearms, $\mathrm{c}$ - in neck, $\mathrm{d}$ - -in shoulders, e-in hip and lower back, f-in feet; 1 -workers who use a desktop computer daily at work, 2-workers who use daily a portable computer or a mini-computer at work.

TABLE 3. Comparison Between Computer Users and Nonusers; an Independent Samples MannWhitney U Test Analysis for Question 16 (Data for Upper- and Lower-Level White-Collar Workers)

\begin{tabular}{|c|c|c|c|c|c|c|}
\hline \multirow[b]{2}{*}{ Participants } & Q16a & Q16b & Q16c & Q16d & Q16e & Q16f \\
\hline & $\begin{array}{l}\text { Asymp. Sig. } \\
\text { (2-tailed) }\end{array}$ & $\begin{array}{l}\text { Asymp.Sig. } \\
\text { (2-tailed) }\end{array}$ & $\begin{array}{c}\text { Asymp. Sig. } \\
\text { (2-tailed) }\end{array}$ & $\begin{array}{l}\text { Asymp. Sig. } \\
\text { (2-tailed) }\end{array}$ & $\begin{array}{l}\text { Asymp.Sig. } \\
\text { (2-tailed) }\end{array}$ & $\begin{array}{c}\text { Asymp.Sig. } \\
\text { (2-tailed) }\end{array}$ \\
\hline \multicolumn{7}{|l|}{ White-collar workers } \\
\hline users $^{1}$-nonusers & .122 & .900 & .970 & .191 & .076 & .187 \\
\hline laptop users ${ }^{2}-$ nonusers & .197 & .625 & .743 & .715 & .791 & .977 \\
\hline female users-nonusers & .458 & .196 & .969 & .555 & $.029^{* *}$ & .117 \\
\hline male users-nonusers & .100 & $.038^{\star *}$ & .899 & .233 & .977 & .872 \\
\hline \multicolumn{7}{|c|}{ Upper-level white-collar workers } \\
\hline users-nonusers & $.013^{\star \star}$ & .947 & .242 & .610 & .110 & $.019^{\star *}$ \\
\hline laptop users-nonusers & .678 & .707 & .774 & .119 & .830 & .469 \\
\hline female users-nonusers & .333 & .265 & .435 & - & .131 & $.004^{* *}$ \\
\hline male users-nonusers & $.009^{\star *}$ & .118 & .450 & .365 & .603 & .505 \\
\hline \multicolumn{7}{|c|}{ Lower-level white-collar workers } \\
\hline users-nonusers & .803 & .887 & .239 & .099 & .417 & .320 \\
\hline laptop users-nonusers & .228 & .971 & .443 & .707 & .313 & .151 \\
\hline female users-nonusers & .674 & .352 & .534 & .180 & .100 & .582 \\
\hline male users-nonusers & .512 & .168 & .288 & .426 & .430 & .378 \\
\hline
\end{tabular}

Notes. ${ }^{* *} p<.05$, asymp. sig.—asymptotic significance; Q16-Have you suffered ... in the past 12 months?; a-sleeping disorders/disturbances, b-depression, c-exhaustion at work, $\mathrm{d}$ - substance addiction, eanxiety, f-fear situations; 1 -workers who use a desktop computer daily at work, 2-workers who use daily a portable computer or a mini-computer at work. 
ence was also significant in women's data, but there were no significant differences in men's data. In addition, in the comparison of daily portable computer or mini-computer users and nonusers, there were significant differences in the ache, pain or numbness in the neck, shoulders, feet and wrists and fingers (in the data of upperlevel white-collar workers).

TABLE 4. Comparison Between Upper- and Lower-Level White-Collar Workers; an Independent Samples Mann-Whitney U Test Analysis for Question 13

\begin{tabular}{|c|c|c|c|c|c|c|}
\hline \multirow[b]{3}{*}{ Participants } & \multicolumn{6}{|c|}{$\begin{array}{l}\text { Q13: Have You Had an Ache, Pain or Numbness in the Following Body Part } \\
\text { During the Past } 12 \text { Months? }\end{array}$} \\
\hline & $\mathbf{a}$ & b & C & d & e & f \\
\hline & $\begin{array}{c}\text { Asymp. Sig. } \\
\text { (2-tailed) }\end{array}$ & $\begin{array}{c}\text { Asymp.Sig. } \\
\text { (2-tailed) }\end{array}$ & $\begin{array}{c}\text { Asymp. Sig. } \\
\text { (2-tailed) }\end{array}$ & $\begin{array}{c}\text { Asymp. Sig. } \\
\text { (2-tailed) }\end{array}$ & $\begin{array}{c}\text { Asymp.Sig. } \\
\text { (2-tailed) }\end{array}$ & $\begin{array}{c}\text { Asymp.Sig. } \\
\text { (2-tailed) }\end{array}$ \\
\hline All workers & $<.001^{\star \star}$ & $.001^{\star \star}$ & $<.001^{\star \star}$ & $<.001^{\star *}$ & $<.001^{* \star}$ & $<.001^{* *}$ \\
\hline Daily desktop computer users & $<.001^{\star \star}$ & $.002^{\star *}$ & $<.001^{\star \star}$ & $<.001^{\star \star}$ & $<.001^{\star *}$ & $.001^{\star *}$ \\
\hline Female desktop computer users & $.003^{\star \star}$ & $.007^{\star \star}$ & $.001^{\star \star}$ & $<.001^{\star \star}$ & $.029^{\star \star}$ & .059 \\
\hline Male desktop computer users & .338 & .936 & .773 & $.023^{\star \star}$ & .208 & .076 \\
\hline $\begin{array}{l}\text { Daily portable computer or } \\
\text { mini-computer users }\end{array}$ & .917 & .849 & .239 & $.048^{\star *}$ & $.016^{\star *}$ & .243 \\
\hline
\end{tabular}

Notes. ${ }^{* *} p<.05$, asymp. sig.-asymptotic significance; a-in wrists and fingers, b-in elbows and forearms, $c$ - in neck, $d$-in shoulders, e-in hip and lower back, f-in feet.

TABLE 5. Results (Type III SS and Significance, Sig.) of a Statistical Analysis for Question 13 (Data for Upper- and Lower-Level White-Collar Workers)

\begin{tabular}{|c|c|c|c|c|c|c|}
\hline \multirow[b]{3}{*}{ Source of Variation } & \multicolumn{6}{|c|}{$\begin{array}{l}\text { Q13: Have You Had an Ache, Pain or Numbness in the Following Body } \\
\text { Part During the Past } 12 \text { Months? }\end{array}$} \\
\hline & a & b & c & d & e & $\mathbf{f}$ \\
\hline & Sig. & Sig. & Sig. & Sig. & Sig. & Sig. \\
\hline \multicolumn{7}{|l|}{ White-collar workers } \\
\hline age & $<.001^{\star *}$ & $<.001^{\star \star}$ & .911 & .334 & .838 & $.003^{\star *}$ \\
\hline gender & $.021^{\star \star}$ & .380 & $<.001^{\star \star}$ & $.018^{\star \star}$ & $.008^{* *}$ & .482 \\
\hline Q11b & .163 & .367 & $.042^{\star \star}$ & .073 & .062 & .464 \\
\hline Q11e & .109 & .314 & .509 & .554 & .247 & .635 \\
\hline Q16b & $<.001^{\star *}$ & $.001^{* *}$ & $<.001^{\star *}$ & $<.001^{\star *}$ & $<.001^{\star *}$ & $<.001^{\star *}$ \\
\hline \multicolumn{7}{|c|}{ two-way interaction } \\
\hline age $\times$ gender & .106 & .729 & .265 & .260 & .299 & .130 \\
\hline \multicolumn{7}{|c|}{ Upper-level white-collar workers } \\
\hline age & .115 & $.003^{\star *}$ & .712 & .210 & .763 & .289 \\
\hline gender & .062 & .598 & $<.001^{\star *}$ & $.002^{\star \star}$ & $.011^{* *}$ & .086 \\
\hline Q11b & .682 & .460 & .290 & .388 & .093 & .384 \\
\hline Q11e & $.048^{\star \star}$ & .166 & .196 & .333 & .288 & .710 \\
\hline Q16b & $<.001^{* *}$ & $.025^{\star \star}$ & $<.001^{\star *}$ & $<.001^{\star \star}$ & $<.001^{\star *}$ & $<.001^{\star *}$ \\
\hline \multicolumn{7}{|c|}{ two-way interaction } \\
\hline age $\times$ gender & .647 & .964 & .242 & .538 & .286 & .712 \\
\hline \multicolumn{7}{|c|}{ Lower-level white-collar workers } \\
\hline age & $.010^{\star *}$ & $.001^{\star *}$ & .585 & .935 & .517 & .059 \\
\hline gender & $.023^{\star \star}$ & .391 & $<.001^{\star *}$ & $.025^{\star \star}$ & $.008^{\star \star}$ & .564 \\
\hline Q11b & .051 & .096 & .190 & .240 & .476 & .692 \\
\hline Q11e & .464 & .744 & .890 & .455 & .166 & .683 \\
\hline Q16b & $.001^{\star *}$ & $.031^{* *}$ & $<.001^{\star *}$ & $<.001^{\star *}$ & $.002^{\star \star}$ & $<.001^{\star *}$ \\
\hline \multicolumn{7}{|c|}{ two-way interaction } \\
\hline age $\times$ gender & .244 & .727 & $.311^{* *}$ & .373 & .213 & .130 \\
\hline
\end{tabular}

Notes. ${ }^{* *} p<.05$; a-in wrists and fingers, b-in elbows and forearms, c-in neck, $\mathrm{d}$-in shoulders, e-in hip and lower back, f-in feet; Q11b-daily use of a desktop computer at work, Q11e-daily use of a portable computer or mini-computer at work, Q16b-depression (pretty often or more frequently). 
Table 3 shows the analyses of Questions 16a-f (mental symptoms). In women's data, there was a difference in the answers on anxiety and fear situations in daily desktop computer users and nonusers. In men's data, there was a difference in the answers on sleeping disorders/disturbances and depression in daily desktop computer users and nonusers. In addition, in the group of upperlevel white-collar workers, there were differences in Q16a (sleeping disorders/disturbances).

Table 4 shows analyses of upper- and lowerlevel white-collar workers. In all the workers' and daily desktop computer users' data, there were differences between all in Questions 13a-f. In women's and men's data, there were also some significant differences in upper- and lower-lever white-collar workers. In daily portable computer or mini-computer users' data, there was a difference only in Q13d (symptoms in the shoulders) and Q13e (symptoms in the hip and lower back).

\subsection{Results of GLM}

Table 5 shows the results of the statistical analyses of answers to Questions 13a-f with the following factors: age, gender, daily use of a desktop computer at work (Q11b), daily use of a portable computer or mini-computer at work (Q11e), depression, pretty often or more frequently (Q16b). The psychological symptom of depression influenced all in Questions 13a-f. The age and gender influenced many physical symptoms. Daily use of a desktop computer at work influenced experienced pain, numbness or aches in the neck (Q13c in white-collar workers' data), and daily use of a portable computer or mini-computer at work influenced experienced pain, numbness or aches in the wrists and fingers (Q13a in upper-level workers' data).

\section{DISCUSSION}

\subsection{Evaluation of Methods}

The study's population was 15000 Finns, and the number of responses was 6121, which is quite a large response. Therefore, it was possible to analyse subgroups of occupations. In these analyses, 4368 responses were used from persons who were in working life. The questionnaire included questions on various topics and questions about work and leisure. Therefore, we were not able to obtain very much information about their working life, and we could only use information on occupations in the analysis. The questionnaire covered a variety occupations: entrepreneurs, farmers, upper-level white-collar workers (administrative or managerial duties, designing, research, teaching), lower-level white-collar workers (clerical duties and supervision) and blue-collar workers (industrial workers, distributive and service trade). The question on occupations had other options: none (never had an occupation); home work and student; and other. The alternatives were quite wide and it is difficult to know precisely what kind of casual work some respondents did. Two groups of occupations, lower-level white-collar workers (clerical duties and supervision) and blue-collar workers (industrial workers, distributive and service trade), were quite large with over 1000 respondents, and two groups (entrepreneurs and farmers) were quite small, with under 400 respondents. We did statistical analyses for white-collar workers (subgroups: upper- and lower-level white-collar workers), because the group was quite large, and those workers quite often used computers.

According to Statistics Finland, $13.0 \%$ of the population were upper-level white-collar workers, and $20.2 \%$ were lower-level white-collar workers in 2004 [16]. In our data, $15.8 \%$ were upper-level white-collar workers and $18.8 \%$ were lowerlevel white-collar workers. Thus, in our data, the number of workers in those occupations was quite similar to the Finnish population in general.

The approach in this study had some limitations. The questionnaire and questions could influence participants, and only those who were active sent back the questionnaire. Also, opinions can change quite quickly as technology develops. Not all participants understood the symptoms in the same way, and the questionnaire did not include all possible questions or symptoms. There could also be other factors which influenced symptoms at work, e.g., the atmosphere in the workplace. 
The use of computers (especially laptops and other portable computers) has increased since our data was collected in 2002-2003. In addition, the use of computers can differ among countries. However, our results may indicate which symptoms will increase in the future when computer use increases. It can be useful to repeat this kind of questionnaire study in the near future in a developed country in Europe, Asia or in the USA.

\subsection{Evaluation of the Number of Physical Symptoms}

In our study, $50.2 \%$ of the working persons had pretty often or more frequently symptoms in the neck, $30.6 \%$ had symptoms in the shoulders and $31.9 \%$ in the hips and lower back. Wahlstedt, Norbäck, Wieslander et al. studied psychosocial and ergonomic factors, and their relation to musculoskeletal complaints using a questionnaire from occupationally active Swedish persons [17]. They reported from men's data that $8 \%$ (21/272) had neck symptoms, $8 \%$ (21/272) had symptoms in the shoulders, $4 \%$ (10/272) had upperback symptoms and 9\% (34/272) had lowerback symptoms. In women's data, the respective number were $11 \%$ (38/260), 17\% (44/260), 9\% (23/260) and $16 \%(41 / 260)$ [17]. In our data, respondents had more symptoms than Swedish workers. However, we studied white-collar workers only and we did not use the same questionnaire as Wahlstedt et al.

Malińska and Bugajska studied the influence of occupational and nonoccupational factors on the prevalence of musculoskeletal complaints in users of portable computers [18]. They studied 300 workers using the Nordic musculoskeletal questionnaire. The study included, e.g., representatives of trade companies (16.7\%), white-collar workers (14.7\%) and personnel or financial and related sectors (12.3\%). Malińska and Bugajska found that the most frequent complaints among computer operators were headaches $(42 \%)$, lower back pain $(38 \%)$ and neck pain $(35 \%)$ [18]. In our study, in the group of upper-level white-collar workers, $45.7 \%$ had pretty often or more frequently physical symptoms in the neck, $24.3 \%$ in the hip and lower back and $23.2 \%$ in the shoulders, and in the group of lower-level white- collar workers, $56.0 \%$ had physical symptoms in the neck, $35.8 \%$ in the shoulders and $32.1 \%$ in the hip and lower back. These results are quite similar to Malińska and Bugajska's data.

\subsection{Comparison of Daily Computer Users' Symptoms and Nonusers' Symptoms}

In daily desktop users compared to nonusers, significant differences were observed in pain, numbness or aches in the neck (Q13c), while in portable computer or mini-computer users versus nonusers, there were significant differences in the prevalence of symptoms in the neck (Q13c), shoulders (Q13d) and in feet (Q13f) (Table 2). Other studies reported neck and upper extremity musculoskeletal symptoms in computer and computer-mouse users, so the differences were not unexpected, but less attention was devoted to the occurrence of musculoskeletal symptoms related to the use of portable computers or minicomputers, so our results, showing an increase of symptoms, seem of interest [19, 20, 21, 22, 23]. In addition, a systematic review of computer work and musculoskeletal disorders of the neck and upper extremity showed, e.g., limited evidence of a causal relationship between computer work per se or computer-mouse (or keyboard) time related to wrist tendonitis, forearm disorders and the tension neck syndrome [24]. So, other researchers also found that the use of computers can be associated with physical symptoms.

Table 3 shows some differences in responses related to sleeping disorders/disturbances, depression, anxiety and fear situations between daily desktop computer users and nonusers. In addition, in the groups of upper-level white-collar workers and women, there were differences in Q16f (fear situations). In our earlier article, we showed how mental symptoms were associated with the use of desktop, portable or mini-computers (communicators and hand-held computers), mobile phones, and background information such as age and gender in the Finnish working-age population [15]. In all data (all respondents), the use of desktop computers was related to mental symptoms. We found similar results when we concentrated on white-collar workers. However, it is interesting that in white-collar male workers' 
data, only the sleeping disorders/disturbances and depression symptoms were different in daily desktop computer users and nonusers. So, in the future, it is important to take into account that computers can influence male workers' sleeping disorders/disturbances and depression symptoms. However, it is important to remember that in this study the words sleeping disorders/disturbances and depression were only self-reported symptoms, not medically diagnosed sleeping disorders/ disturbances or depression.

\subsection{Comparison of Upper- and Lower- Level White-Collar Workers}

When comparing all upper- and all lower-level white-collar workers, there were differences in all physical symptoms in Questions 13a-f (Table 4). The same was true when comparing desktop computer users and nonusers. In men's data, there was a difference in Q13d (symptoms in the shoulders) only. It is difficult to explain those differences, but perhaps the use of computers was different. For example, Table 1 shows $25.8 \%$ of male upper-level white-collar workers used a portable computer or mini-computer daily and only $7.5 \%$ of lower-level white-collar male workers had similar use. The difference in the use of a portable computer or mini-computer can explain the significant differences in Q13d (symptoms in the shoulders) and Q13e (symptoms in the hip and lower back). In women's data, there were also several differences. However, this is quite easy to understand, because according to Straker, Smith, Bear, et al. gender has an effect on the relationships among computer use, posture and neck/shoulder pain [4]. Wahlstedt et al. studied psychosocial and ergonomic factors, and their relation to musculoskeletal complaints in the Swedish workforce [17]. They found that females reported more symptoms in the neck, shoulders and upper back than males. We also had different results in women's and in men's data. However, analysing the data, it is important to take into account that there were fewer women in upperlevel white collar workers $(49.3 \%)$ than in lowerlevel ones $(69.3 \%)$.

\subsection{Analysis of GLM Results}

Age and gender had some influence on many physical symptoms (Questions 13a-f) and depression had an influence on all in Questions 13a-f (Table 5). The literature also shows that stress is a common problem in working life, and that it is related to psychosocial factors and may be associated with musculoskeletal complaints [8, 12]. Therefore, it is possible to understand that in our data depression influenced physical symptoms. We also had some influence related to topics other than the use of computers.

Daily use of a desktop computer at work (Q11b) influenced experienced pain, numbness or aches in the neck $(\mathrm{Q} 13 \mathrm{c}$ in white-collar workers' data) and daily use of a portable computer or mini-computer at work influenced experienced pain, numbness or aches in the wrists and fingers (Q13a in upper-level workers' data). The result from Q13c supported our results from the comparison of daily computer users' and nonusers' symptoms.

White-collar workers quite often used different computers. A large-scale questionnaire offers a good reference for evaluating the prevalence of white-collar workers' symptoms resulting from using modern electrical devices. Finland is a leading country in the design and use of electronics and thus offers an interesting viewpoint on such issues. Our data supports the idea of paying more attention to computer-related physical symptoms in future studies, especially in the research of new devices, such as tablets.

\section{CONCLUSION}

In conclusion, the results of this questionnaire study, based on over 6000 answers from workers aged 18-66 years, show that $50.2 \%$ of Finnish workers pretty often or more frequently experienced pain, numbness and aches in the neck. In the group of upper-level white-collar workers, the proportion of participants with symptoms was $45.7 \%$, while in lower-level white-collar workers it was $56.0 \%$. When comparing daily desktop computer users and nonusers, there were significant differences in pain, numbness or aches pretty 
often or more frequently in the neck, and when comparing portable computer or mini-computer users and nonusers, there were the significant differences pretty often or more frequently in the neck, in the shoulders and in the feet. However, in evaluating the results, we have to consider that age and gender had some influence on physical symptoms. In the future, it is essential to take into account that workers' physical symptoms in the neck can be associated with their use of a desktop computer, and symptoms in the neck and shoulders can be associated with the use of a portable computer or a mini-computer.

\section{REFERENCES}

1. Parent-Thirion A, Fernández Macías E, Hurley J, Vermeylen G. Fourth European working conditions survey. Luxembourg: Office for Official Publications of the European Communities; 2007. Retrieved August 29, 2011, from: http://www. eurofound.europa.eu/pubdocs/2006/98/ en/2/ef0698en.pdf

2. Perkiö-Mäkelä M, Hirvonen M, Elo A, Ervasti J, Huuhtanen P, Kandolin I, et al. Work and health-interview study. Report of tables. Helsinki, Finland: Finnish Institute of Occupational Health; 2006. In Finnish.

3. Gourmelen J, Chastang J-F, Ozguler A, Lanoë J-L, Ravaud J-F, Leclerc A. Frequency of low back pain among men and women aged 30 to 64 years in France. Results of two national surveys. Ann Readapt Med Phys. 2007;50:640-4.

4. Straker LM, Smith AJ, Bear N, O'Sullivan PB, de Klerk NH. Neck/shoulder pain, habitual spinal posture and computer use in adolescents: the importance of gender. Ergonomics. 2011;54(6):539-46.

5. Statistics Finland. Consumer survey 2008. In Finnish. Retrieved August 29, 2011, from: http://www.stat.fi/til/kbar/2008/02/ kbar_2008_02_2008-02-29_kuv_014.html

6. Statistics Finland. Table 6. Number of mobile phone subscriptions and number of subscriptions per 100 population in 1980 , 1985 and 1990-2006. 2007. Retrieved August 29, 2011, from: http://www.stat. fi/til/tvie/2006/tvie_2006_2007-06-05_ tau_006_en.html

7. Statistics Finland. 2. Still more adults use computers. 2008. In Finnish. Retrieved August 29, 2011, from: http:// www.stat. fi/til/aku/2006/03/aku_2006_03_2008-0603_kat_002_fi.html

8. Eklöf M, Ingelgård A, Hagberg M. Is participative ergonomics associated with better working environment and health? A study among Swedish white-collar VDU users. Int J Ind Ergon. 2004;34(5):355-66.

9. Kuorinka I, Forcier L, Hagberg M, Silverstein B, Wells R, Smith MJ, et al. Work related musculoskeletal disorders (WMSDs): a reference book for prevention. London, UK: Taylor \& Francis; 1995.

10. National Institute for Occupational Safety and Health (NIOSH). Workrelated musculoskeletal disorders and psychosocial factors. In: Bernard B, editor. Musculoskeletal disorders and workplace factors (DHHS (NIOSH) publication No. 97-141). Cincinnati, OH, USA: NIOSH; 1997. p. 7-1-16. Retrieved August 29, 2011, from: http://www.cdc.gov/niosh/ docs/97-141/pdfs/97-141.pdf

11. Bongers PM, Kremer AM, ter Laak J. Are psychosocial factors risk factors for symptoms and signs of the shoulder, elbow or hand/wrist?: a review of the epidemiological literature. Am J Ind Med. 2002;41(5):315-42.

12. Pransky G, Robertson MM, Moon SD. Stress and work-related upper extremity disorders: implications for prevention and management. Am J Ind Med. 2002; 41(5):443-55.

13. Eklöf M, Hagberg M. Are simple feedback interventions involving workplace data associated with better working environment and health? A cluster randomized controlled study among Swedish VDU workers. Appl Ergon. 2006;37(2):201-10.

14. Korpinen L, Suuronen N, Latva-Teikari J, Pääkkönen R. A questionnaire on the health effects of new technical equipment. Int $\mathrm{J}$ Ind Ergon. 2009;39(1):105-14.

15. Korpinen L, Pääkkönen R. Mental symptoms and the use of new technical equipment. International Journal of Occupational Safety and Ergonomics 
(JOSE). 2009;15(4):385-400. Retrieved August 29, 2011, from: http://www.ciop. $\mathrm{pl} / 33826$

16. Statistics Finland. Statistical yearbook of Finland 2007. Helsinki, Finland: Official Statistics of Finland; 2007.

17. Wahlstedt K, Norbäck D, Wieslander G, Skoglund L, Runeson R. Psychosocial and ergonomic factors, and their relation to musculoskeletal complaints in the Swedish workforce. International Journal of Occupational Safety and Ergonomics (JOSE). 2010;16(3):311-21. Retrieved August 29, 2011, from: http://www.ciop. $\mathrm{pl} / 37945$

18. Malińska M, Bugajska J. The influence of occupational and non-occupational factors on the prevalence of musculoskeletal complaints in users of portable computers. International Journal of Occupational Safety and Ergonomics (JOSE). 2010;16(3):337-43. Retrieved August 29, 2011, from: http://www.ciop.pl/37948

19. Blatter BM, Bongers PM. Duration of computer use and mouse use in relation to musculoskeletal disorders of neck or upper limb. Int J Ind Ergon. 2002;30(4-5): 295-306.
20. Cook C, Burgess-Limerick R, Papalia S. The effect of upper extremity support on upper extremity posture and muscle activity during keyboard use. Appl Ergon. 2004;35(3):285-92.

21. Crawford JO, Laiou E, Spurgeon A, McMillan G. Musculoskeletal disorders within the telecommunications sector-a systematic review. Int J Ind Ergon. 2008;38(1):56-72.

22. Ming Z, Zaproudina N. Computer use related upper limb musculoskeletal (ComRULM) disorders. Pathophysiology. 2003;9(3):155-60.

23. Village J, Rempel D, Teschke K. Musculoskeletal disorders of the upper extremity associated with computer work: a systematic review. Occup Ergon. 2005;5(4):205-18.

24. Waersted M, Hanvold TN, Veiersted KB. Computer work and musculoskeletal disorders of the neck and upper extremity: a systematic review. BMC Musculoskelet Disord. 2010;11:79. Retrieved August 29, 2011, from: http://www.ncbi.nlm.nih.gov/ pmc/articles/PMC2874766/?tool=pubmed 